\title{
A Detailed Look at the Saturate Fractions of Different Crude Oils Using Direct Analysis by Ultrahigh Resolution Mass Spectrometry (UHRMS)
}

\author{
Zahra Farmani and Wolfgang Schrader *(D) \\ Max-Planck Institut für Kohlenforschung, Kaiser-Wilhelm Platz 1, D-45470 Mülheim an der Ruhr, Germany \\ * Correspondence: wschrader@mpi-muelheim.mpg.de
}

Received: 25 July 2019; Accepted: 30 August 2019; Published: 7 September 2019

\begin{abstract}
SARA (Saturates, Aromatics, Resins, Asphaltenes) fractionation is a common simplification technique used for decades in petrochemical analysis. A large number of studies are dealing with the different fractions, but overall, the saturate fraction is strongly neglected. Of the very few available studies on the saturates fraction, almost all have been performed using gas chromatographic (GC) techniques. This discriminates the results of the saturate fraction especially since non-volatile, high molecular weight and polar constituents are mostly excluded. Here, for the first time, saturate fractions of different crude oils from different origins are analyzed using direct infusion ultrahigh resolution mass spectrometry (UHRMS), to study the compositions on a molecular level. Electrospray (ESI), atmospheric pressure chemical ionization (APCI) and atmospheric pressure photoionization (APPI) are used in positive mode. The observed results show the presence of different heteroatom containing classes, with different chemical identities (i.e., presence of thiophenes, mercaptans and cyclic-sulfides in case of S-containing compounds). These results show the high affinity of some specific compounds towards different ionization techniques. Finally, the saturate fraction is shown to include much more than only volatile, saturated and aliphatic compounds. The detected compounds in this fraction present a very wide variety, not only in terms of their carbon atoms per molecule and their aromaticity, but also with regard to their functional groups and structural arrangements.
\end{abstract}

Keywords: SARA fractionation; saturates; crude oil analysis; mass spectrometry

\section{Introduction}

A better understanding of the properties and behavior of crude oil during different (petroleum) processes (i.e., extraction, transportation and refining), requires a thorough knowledge about its chemical composition [1]. Crude oil is one of the most complex chemical mixtures in the world. Some reports indicate the presence of more than $10^{6}$ chemical compounds in crude oil samples [2]. These compounds include aliphatic and polyaromatic hydrocarbons, different types of hetero-cycles $(\mathrm{N}, \mathrm{O}, \mathrm{S})$ as well as some trace amount of metals [3,4], which differ not only in molecular weight, but also in polarity and structure. Due to this high complexity, there is no single analytical technique that can fully characterize a crude oil and provide detailed chemical information on the molecular level. Therefore, performing a pre-simplification step is a requirement to get a deeper knowledge of the chemical constituents of the conventional crude oil sample [1,5]. One of the most commonly used simplification techniques for petroleum samples is the so-called SARA fractionation. SARA is the acronym for the different fractions resulting from this technique (Saturate, Aromatics, Resin and Asphaltene). This fractionation technique was first introduced by Jewel et al. [6] and was further studied, developed and optimized in the last decades by various research groups [1,7-10]. SARA fractionation is based on the solubility, polarity and adsorption affinity of the different petroleum compounds $[3,9]$. 
Because of the irreversible adsorption affinity of asphaltenes to the stationary phase, the initial step is precipitation of asphaltenes using a paraffinic solvent (e.g., $n$-heptane or pentane). Later, the remaining portion of the crude oil (maltenes) are further fractionated to saturates, aromatics and resins by column chromatography using different solvents [3,10-12]. Saturates, referring to their chemically descriptive name, are known to contain mainly nonpolar compounds including linear, branched and cyclic saturated hydrocarbons. To date, there are very few studies focusing on the saturate fraction, almost all of which were performed using gas chromatographic (GC or GCxGC) techniques. Among those, GC-flame ionization detection (GC-FID) [12-15] and hyphenation of GC to mass spectrometry (GC-MS) $[9,13,16,17]$ are the most commonly used techniques for petroleum analysis. Still, the major drawback is that the components have to be volatile and stable enough to be thermally evaporated to pass through the GC, therefore limiting the mass range and aromaticity. A recent study describes the potential and limitations of GC/HR-MS using different ionization methods [18].

Ultrahigh resolution mass spectrometry (UHRMS) is the method of choice for investigation of complex mixtures [2,19-25]. Thanks to the ultrahigh resolving power and based on accurate mass measurements, UHRMS provides unique elemental compositions $\left(\mathrm{C}_{\mathrm{c}} \mathrm{H}_{\mathrm{h}} \mathrm{N}_{\mathrm{n}} \mathrm{O}_{\mathrm{o}} \mathrm{S}_{\mathrm{s}}\right)$ for the detected compounds [11,22]. However, the main disadvantage of GC in this context is the discrimination in detection of all present compounds in the saturate fraction, especially since non-volatile, high molecular weight and polar compounds are mostly excluded in case they are present in the fraction. Therefore, the GC hyphenation techniques result in detecting only a small part from the total image of the saturate fraction constituents. In this study, saturate fractions of three different oils were analyzed by ultrahigh resolution mass spectrometry after direct infusion. One on the known challenges in any MS analysis is the discrimination and suppression effects of some compounds, which might occur during ionization [26,27]. Therefore, in order to get a more in depth knowledge about the chemical characteristics of the saturate fraction, the samples were analyzed using three different atmospheric pressure ionization (API) methods: Electrospray ionization (ESI), which is primarily used for the analysis of large, polar, heteroatom containing compounds [28-31]; atmospheric pressure chemical ionization (APCI), which is known to be suitable for the analysis of small to moderately large size non-polar molecules (e.g., saturated or partially unsaturated compounds) [32,33]; and atmospheric pressure photoionization (APPI), which is reported as an optimal ionization method for the investigation of aromatic petroleum hydrocarbons and the sulfur containing species in petroleum [34-36]. Results of the three different ionization methods are compared.

\section{Materials and Methods}

\subsection{SARA Fractionation}

Crude oils for this study were selected from three different origins: A light oil from East Asia, a medium oil of Arabic origin and a heavier oil from Eurasia. A total of $6 \mathrm{~g}$ of each oil was collected and the asphaltenes were separated using a modified IP-143 method, which is described in detail elsewhere $[26,28]$. Of the remaining maltenes from each oil, $1 \mathrm{~g}$ was mixed with the silica sorbent (Silicalgel 60, 40-63 $\mu \mathrm{m}$, Merck KGaA, Darmstadt, Germany) which later was loaded on an individual pre-column $(75 \mathrm{~mm} \times 12 \mathrm{~mm})$. Separation of the maltenes was performed using an automated open column chromatography system (Sepecore X10, Büchi, Labortechnik GmbH, Essen, Germany equipped with a UV-Vis Detector C-640 (Büchi, Labortechnik GmbH, Essen, Germany)) using cartridges $\left(150 \mathrm{~mm} \times 12 \mathrm{~mm}\right.$, packed with silica sorbent) and a solvent flow rate of $3 \mathrm{~mL} \mathrm{~min}^{-1}$. The saturate, aromatic, resin I and resin II fractions where eluted using cyclohexane, cyclohexane:dichloromethane $(1: 1, v / v)$, methanol and ethyl acetate, respectively [10]. Elution of the single fractions was maintained using the UV-absorption of the effluent at $254 \mathrm{~nm}$. The collected fractions were evaporated to dryness and stored for further analysis. More details about the SARA fraction ratios of the three crudes are shown in Figure 1. 


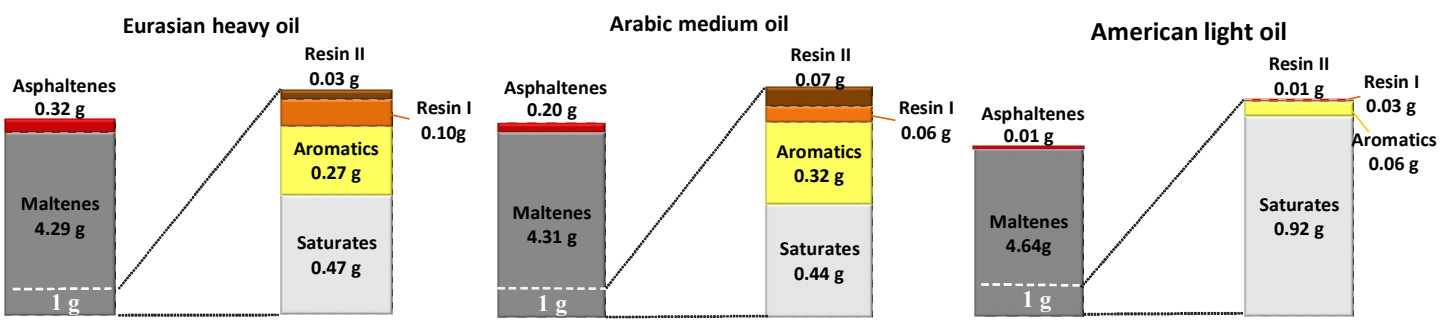

Figure 1. Detailed charts from the extracted amount of asphaltenes and maltenes from $6 \mathrm{~g}$ of crude oil, and further extracted saturates, aromatics, resin I and II from $1 \mathrm{~g}$ of maltenes of heavy Eurasian oil (left), Arabic medium oil (middle) and American light oil (right).

\subsection{UHRMS Sample Preparation}

For direct infusion, saturate samples were diluted in a toluene: methanol $(1: 1, v / v)$ mixture to a final concentration of $250 \mu \mathrm{g} \mathrm{mL}-1$ and then analyzed with no further treatment.

\subsection{Instrumentation and Methods}

Mass spectra were recorded on a research-type Orbitrap Elite mass spectrometer (Thermo Scientific, Bremen, Germany). The recorded mass range was $m / z 200-1200$, using spectral stitching (mass windows of 30 Da with 5 Da overlap), at a mass resolving power of $R=480,000$ (FWHM at $m / z 400$ ).

\subsection{Ionization Methods}

Electrospray ionization (ESI): The sample solutions were introduced at a flow rate of $5 \mu \mathrm{L} \mathrm{min}{ }^{-1}$. The ionization was performed in positive mode at a spray voltage of $4.2-4.7 \mathrm{kV}$. Nebulization was assisted by a sheath gas flow of 5-7 arbitrary units. The flow rate of the auxiliary gas and sweep gas were optimized and set accordingly to 3-5 and 1-2 arbitrary units for each sample.

Atmospheric pressure chemical (APCI): The flow rate of the sample was set at $5 \mu \mathrm{L} \mathrm{min}{ }^{-1}$. The ionization was performed in positive mode, at a corona discharge current of 5-6 $\mu \mathrm{A}$. The heated sprayer was operated at $350^{\circ} \mathrm{C}$.

Atmospheric pressure photoionization (APPI): The flow rate of sample infusion was $7 \mu \mathrm{L} \mathrm{min}{ }^{-1}$. The ionization was performed in positive mode. A Krypton VUV lamp (Syagen Technologies, Tustin, CA, USA) with a photon emission at 10.0 and $10.6 \mathrm{eV}$ was used for ionization. The heated sprayer was operated at $350{ }^{\circ} \mathrm{C}$.

For all analysis performed using different ionization methods, the transfer capillary temperature was set at $275^{\circ} \mathrm{C}$.

\subsection{Data Analysis}

The acquired data were analyzed by Composer64 Version 1.5.0 (Sierra Analytics, Inc., Modesto, USA). For peak assignment the following criteria were applied: $0 \leq H \leq 1000,0 \leq C \leq 200,0 \leq N \leq 3$, $0 \leq O \leq 3,0 \leq S \leq 3$, and $0 \leq D B E \leq 80$ with a maximum mass tolerance of $1 \mathrm{ppm}$.

During evaluation, double bond equivalent (DBE) is used as an important parameter to compare the unsaturation degree of different components. DBE refers to the sum of the ring closures and the number of double bonds within a molecule. This value can be calculated from the molecular formula $\left(\mathrm{C}_{\mathrm{c}} \mathrm{H}_{\mathrm{h}} \mathrm{N}_{\mathrm{n}} \mathrm{O}_{\mathrm{o}} \mathrm{S}_{\mathrm{s}}\right)$ of each individual assignment, using the following equation:

$$
\mathrm{DBE}=\mathrm{c}-h / 2+n / 2+1 .
$$




\section{Results}

\subsection{SARA Fractionation}

The extracted saturate fractions from the three different oils are shown in Figure 2. Of the three crudes in this study, the E. Asian light oil had the highest amount of saturates ( $0.92 \mathrm{~g}$ in $1 \mathrm{~g}$ of maltenes), followed by the heavy Eurasian oil ( $0.47 \mathrm{~g}$ in $1 \mathrm{~g}$ of maltenes) and the Arabic medium oil ( $0.43 \mathrm{~g}$ in $1 \mathrm{~g}$ of maltenes).

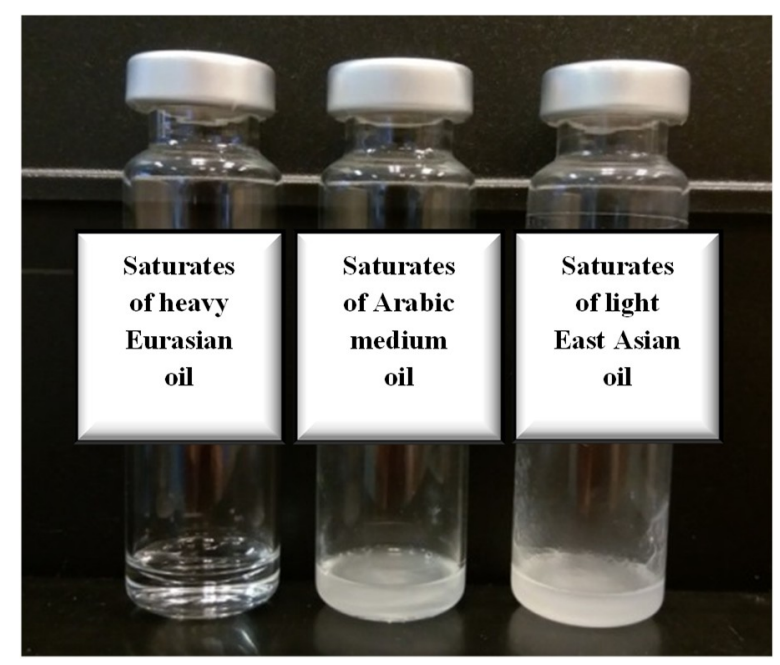

Figure 2. Saturate fractions of heavy Eurasian oil (left), Arabic medium oil (middle) and E. Asian light oil (right).

\subsection{UHRMS Measurements}

Results of direct infusion of different saturates show that the constituents of these samples were not only hydrocarbons, but also the heteroatom containing classes $\left(\mathrm{N}, \mathrm{NO}, \mathrm{NS}, \mathrm{S}_{\mathrm{x}}\right.$ and $\mathrm{O}_{\mathrm{x}}$ ).

Figure 3 shows the population-based (number of assigned elemental compositions) class distribution of the different saturate fractions using three different ionization techniques. Measurements using ESI (grey bars) in all samples, show a larger variety of compound classes with polar moieties (especially N-containing classes) as expected [28-30]. Results of the measurements of the same samples using APCI (red bars) and APPI (blue bars) show similarities in the type of detected compound classes. In all of the samples, APCI and APPI measurements show a higher number of hydrocarbon compounds and $\mathrm{O}$-containing compound classes. These results comply with the reports in the literature regarding the favored compound classes for APCI(+) and APPI(+) ionization techniques $[32,33]$.

Spectra of the measurement of saturates from the Arabic medium oil, using different ionization methods are shown in Figure 4 as an example. The spectrum of ESI(+) measurement shows a distribution in a smaller mass range $(\mathrm{m} / \mathrm{z} 200-550)$ compared to the $\mathrm{APCI}(+)$ and $\mathrm{APPI}(+)$ measurements $(\mathrm{m} / \mathrm{z} 200-\mathrm{ca}$. 1000). In all measurements, the highest abundant series of peaks are related to $S_{1}$ class compounds with a DBE of 6 . For the $\mathrm{ESI}(+)$ and the $\mathrm{APCI}(+)$ spectra these peaks are observed as protonated molecules $\left([\mathrm{M}+\mathrm{H}]^{+}\right)$, while the APPI $(+)$spectrum shows predominantly radical cations $\left(\left[\mathrm{M}^{+}\right]\right)$. 


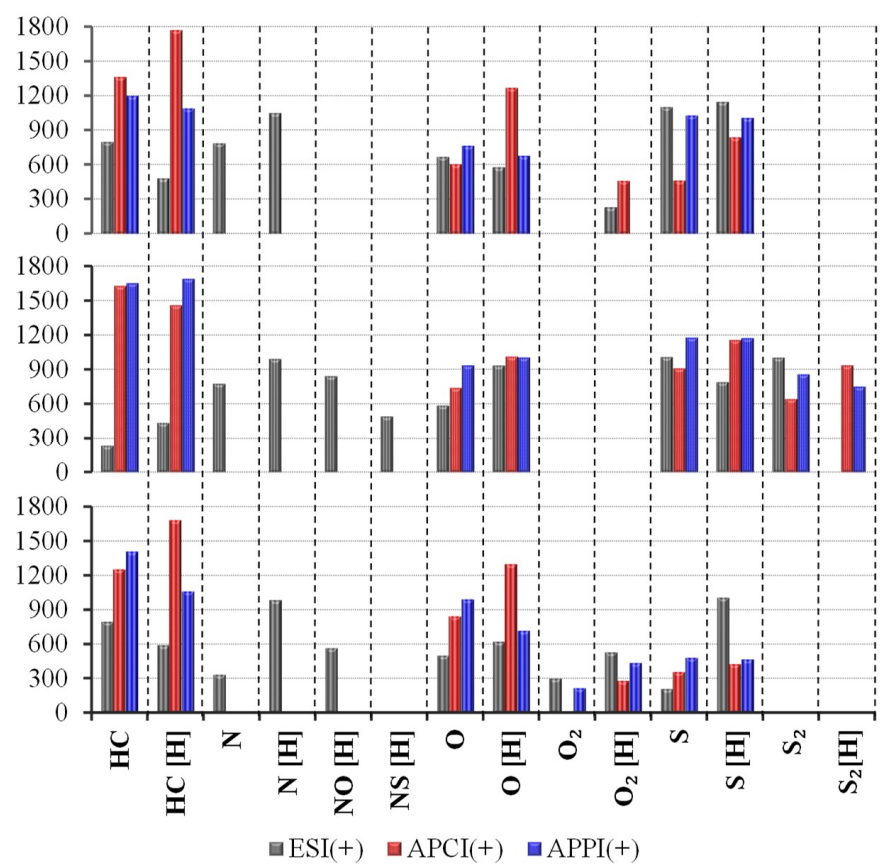

Figure 3. Population-based class distribution of the detected compound classes of heavy Eurasian oil (top), Arabic medium oil (middle) and E. Asian light oil (bottom), using different ionization techniques: Electrospray (ESI(+)) (grey), atmospheric pressure chemical ionization $(\mathrm{APCI}(+))($ red) and atmospheric pressure photoionization (APPI(+)) (blue).

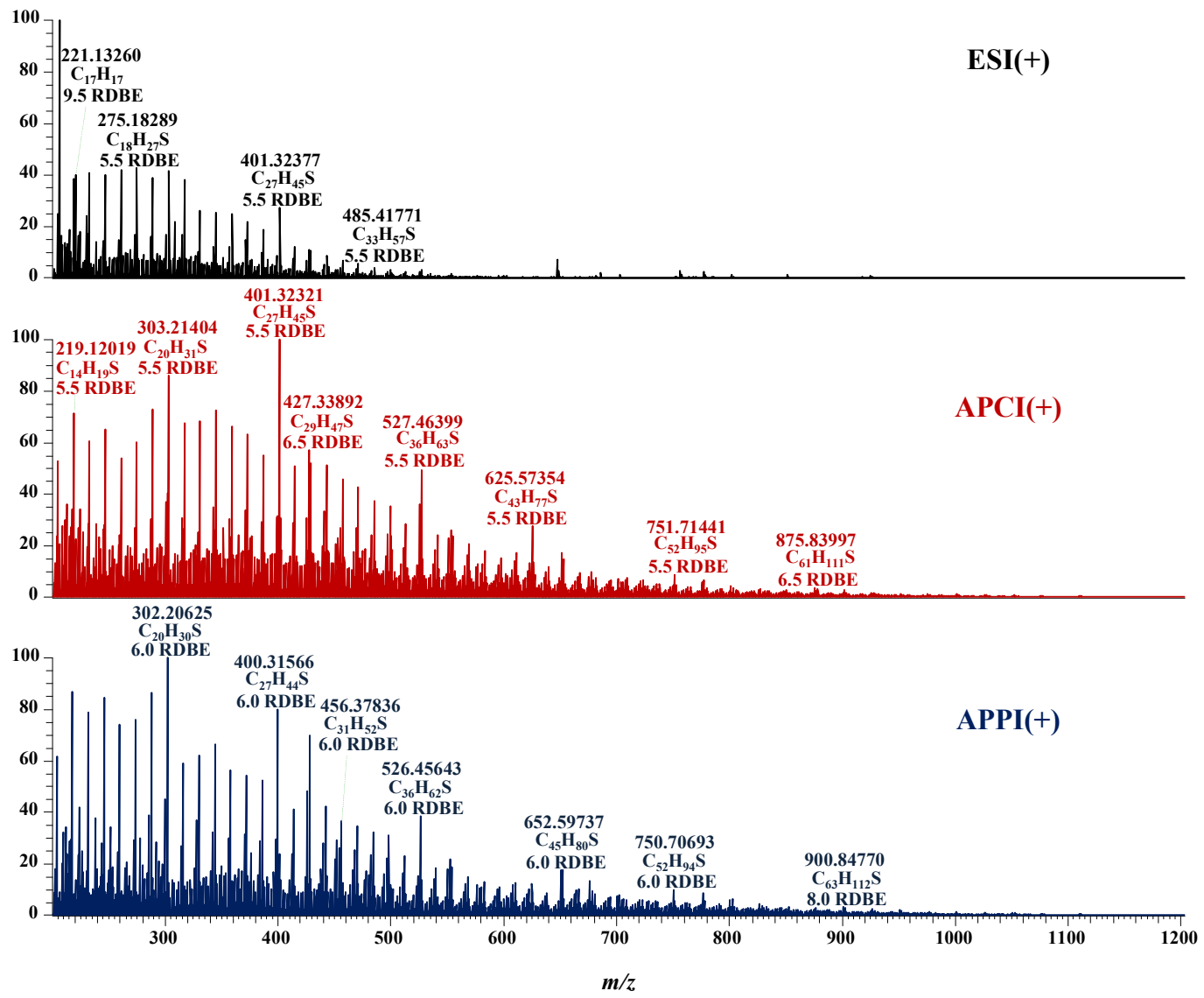

Figure 4. Spectra of saturates from Arabic medium oil in the mass range of $m / z$ 200-1200, using different ionization techniques: $\mathrm{ESI}(+)$ (top), $\mathrm{APCI}(+)$ (middle) and $\mathrm{APPI}(+)$ (bottom). 
The class distribution in Figure 3 indicates the complexity of the different samples, increased by using different ionization methods. Here, we focus on the different $\mathrm{S}$ classes for comparison because they show high intensity in the spectra and are compounds of importance due to their environmental impact. Additionally, S-species have a tendency to be neglected or misassigned in the GC intermediated studies [37,38]. More detailed information about the molecular constitution of the S[H] and S class of the samples are presented in Figures 5-7. Figure 5 shows Kendrick plots of the S[H] class for the ESI(+) measurements of the different saturate samples.
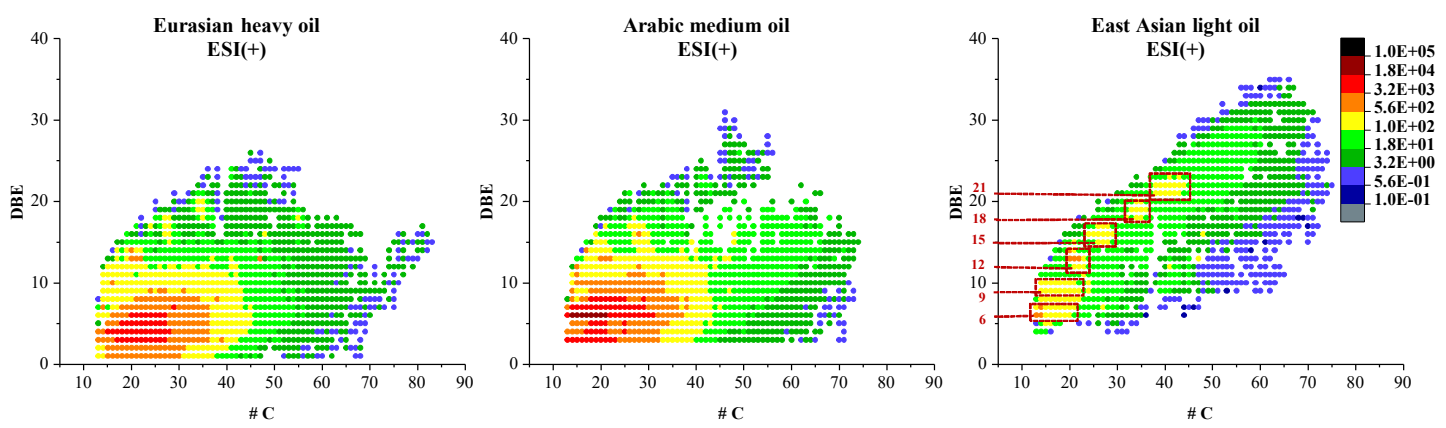

Figure 5. Kendrick plots of the S[H] class for ESI(+) measurements of saturates from Eurasian heavy oil (left) Arabic medium oil (middle) and E. Asian light oil (right). Color-coding represents the intensity of the corresponding monoisotopic signal.
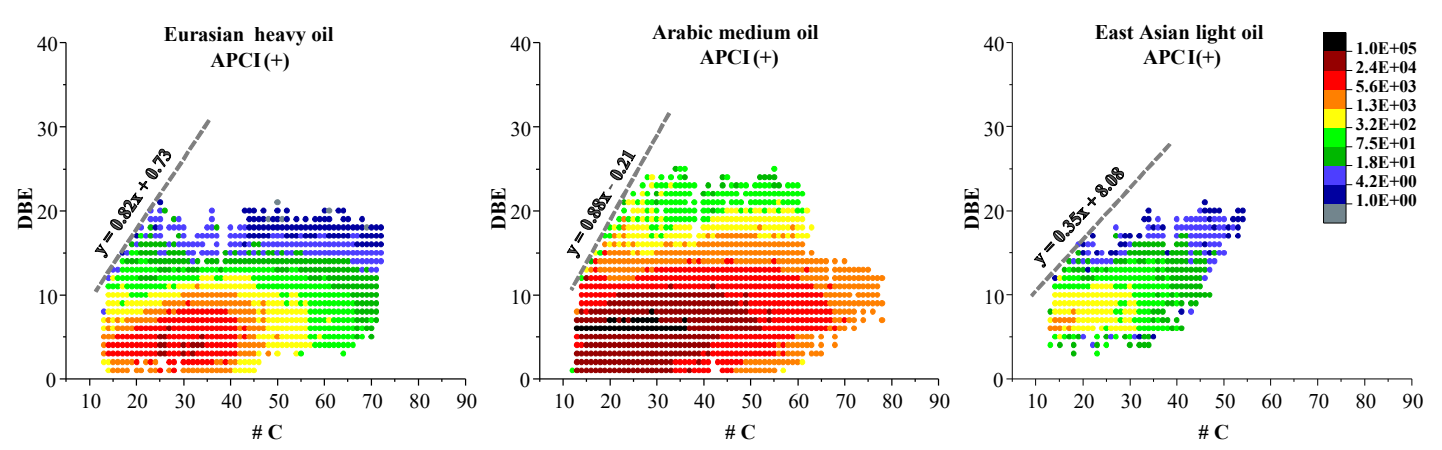

Figure 6. Kendrick plots of the $\mathrm{S}[\mathrm{H}]$ class for $\mathrm{APCI}(+)$ measurements of saturates from Eurasian heavy oil (left) Arabic medium oil (middle) and E. Asian light oil (right). Color-coding represents the intensity of the corresponding monoisotopic signal.
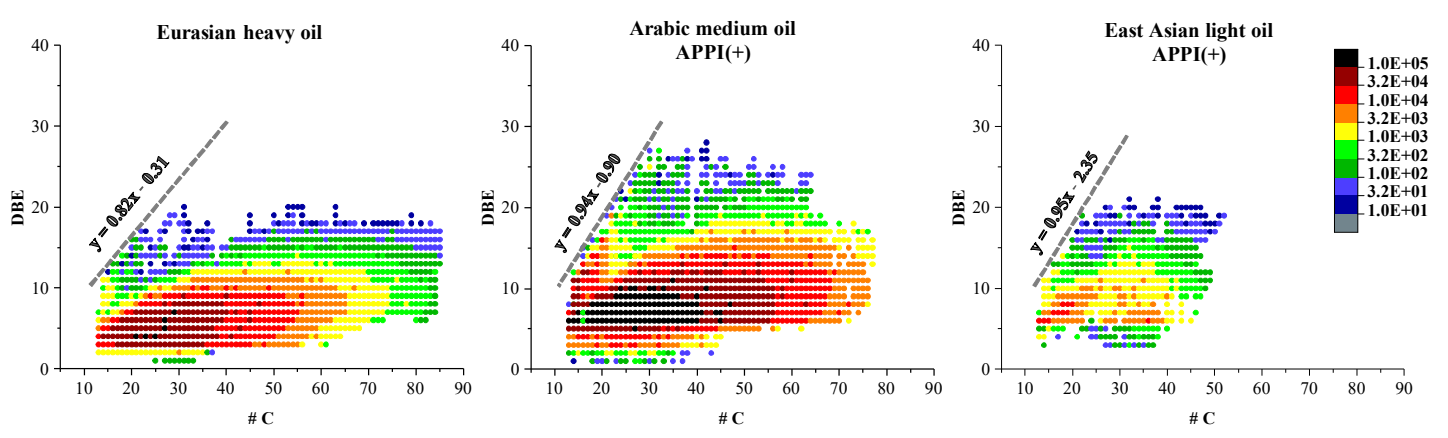

Figure 7. Kendrick plots of the S class for APPI(+) measurements of saturates from Eurasian heavy oil (left) Arabic medium oil (middle) and E. Asian light oil (right). Color-coding represents the intensity of the corresponding monoisotopic signal.

In these graphs, each dot represents one assigned composition within the $\mathrm{S}[\mathrm{H}]$ class of compounds according to the number of carbon atoms within the corresponding neutral molecule and the resulting DBE value. Color-coding represents the intensity of the corresponding monoisotopic peak. 
Assignments for all three samples are in the range below 75 carbon atoms, and below a DBE value of 35. The compared distributions are generally broader for the heavy and medium oils, i.e., these oils contain compounds with more carbon atoms in alkyl chains than the saturate from the light oil. Saturates from the Eurasian heavy oil include assignments with a DBE value of 1 and 2, which are unique for this sample. Such compounds are non-aromatic and can only belong to the group of mercaptanes with one or two naphtenic rings or (cyclic) sulfides (e.g., thiolanes), both of which are known S-species in crude oils $[37,38]$.

For the saturate fraction from the light oil, the high abundance region of compounds found for the other samples (below carbon atom number 25 and max. DBE value 10) is less pronounced. Instead, the Kendrick plot shows the presence of some hotspots with carbon and DBE values, which show a higher intensity than their neighboring assignments. These higher intensity regions are present in the other two saturate samples, but are far less pronounced. These high intensity regions are repeated in DBE interval values of $3(6,9,12, \ldots$ up to 21$)$, which differ in 4 to 6 carbon atoms. According to the reports on the different $S$ species, these results indicate compounds which belong to the thiophenic group of compounds [39].

Figure 6 shows the corresponding Kendrick plots from the APCI(+) measurements. The overall distributions for the heavy and the medium oils, similar to ESI(+) measurements, are broader than for the light oil. Meanwhile, compositions of DBE 1 and 2 are found in both of the saturates from Arabic medium and Eurasian heavy oil. These compounds are again related to mercaptanes or (cyclic) sulfides, which were also observed in ESI(+) measurements. Assignments for the Eurasian heavy oil and the E. Asian light oil reach a DBE value of 20 with high intensities below DBE 10, while the Arabic medium oil reaches a DBE of 25 with highest intensities up to DBE 17. For the Eurasian oil the majority of the compounds with a higher number of alkyl carbon atoms are between DBE values of 3 to 20 (with up to 70 carbon atoms), while in the Arabic oil the distribution starts from DBE 1 to 15 (with up to 80 carbon atoms). In the case of Arabic medium oil, the above-mentioned distribution is also the high intensity region of the plot. The high intensity region in the distribution of Arabic medium oil (DBE below 20) shows detection of a series of compounds with a high degree of alkylation. This is due to the high response factor of non-polar and alkylated compounds towards $\mathrm{APCI}(+)$, which is reported in the available literature [40-42].

Figure 6 shows the trend lines (and the corresponding equations) marked by the highest compounds detected in the DBE range 12-20. The slopes of these lines indicate the so-called planar limit (in this case Planar Saturate Limit (PSL)) which has been studied by Kim and co-workers [43]. The PSL for saturates of the Eurasian heavy and Arabic medium oils show a slope of 0.82 and 0.88 correspondingly. These values are in the range between 0.75 and 1 , which have been attributed to the addition of aromatic and condensed aromatic rings. These highly aromatic compounds are only limited to a small region (below 25 carbon atoms) of the total distribution in the plot. These compounds are small condensed aromatic molecules, which are supposed to belong to the aromatic fraction. SARA fractionation is based on solubility, polarity and adsorption, and a complete separation of the different fractions without any overlap cannot be expected $[1,9,16]$. In case of light oil, the value of this slope is 0.35 , which is slightly higher than the reported PSL in the work of Kim and co-workers (0.25) [43]. Therefore, the slope value of 0.35 indicates presence of partially unsaturated naphthenic rings in the structure of the present series of compounds. The above mentioned values are only a structural indicator for the present compounds in the upper limit of the distribution. Hence, the PSL cannot provide a fair judgment about the major structures of the present compounds in the entire sample. Comparison of the presented PSLs and total distributions in the three samples of this study shows that the abundant structures present in each sample are different from one sample to another. Meanwhile, the present compounds in one saturate sample possess very different structural compositions, which can be better studied using a combination of different ionization methods.

The corresponding Kendrick plots of the S class from the APPI(+) measurements are shown in Figure 7. Similar to the APCI(+) results, these distributions also indicate a high degree of alkylation for 
the saturates from the heavy and the medium oils and are slightly broader compared to those from ESI(+) measurements of the same samples. This similarity in observation for the measurements of the same sample using different ionization methods, confirms the presence of more carbon atoms in alkyl chains in the saturates from Eurasian heavy oil and Arabic medium oil. Assignments for the Eurasian heavy oil reach a DBE value of 20 with high intensities between 3 and 10, while the Arabic medium oil reaches a DBE of 30 with highest intensities between 6 and 15. The distribution is narrower for the E. Asian light oil, therefore the degree of alkylation seems limited, as above, and the DBE value also does not exceed 20. For the Arabic medium oil the distributions exceeding a DBE value of 20 represent a continuum of compounds with abundance maxima between 20 to 65 carbon atoms. Additionally, compositions of DBE 1 and 2 are found in the saturates from Arabic medium oil, as oppose to the ESI $(+)$ results for the same sample. The compounds are again attributed to the mercaptanes and (cyclic) sulfides.

PSL values of the three samples were once again calculated for the APPI $(+)$ measurements. These values are in the range between 0.75 and 1 (similar to the $\mathrm{APCI}(+)$ measurement results), which according to the aforementioned literature correspond to presence of aromatic and condensed aromatic systems in the structure of the detected compounds. Similar to what was presented earlier in the APCI measurement results, these condensed aromatic compounds are below 25 carbon atoms, which are supposed to belong to the aromatic fractions. The PSL value of the E. Asian light oil in APPI(+) measurement (0.95) shows detection of more condensed aromatic cores compared to the results of $\mathrm{APCI}(+)$ measurements $(0.35)$ for the same sample. This is as a result of the high ionization efficiency of condensed polycyclic aromatic hydrocarbons (PAHs) and their corresponding heteroatom containing classes (PAXHs) using APPI(+) [44,45]. In Figure 7 the high intensity region in the Kendrick plot for the saturates of Arabic medium oil is shown in the DBE range of 6 to 9, between 12 to 40 carbon atoms. The APPI(+) spectrum of Arabic medium oil in Figure 3 also shows the highest abundant peaks with the chemical formula assignments of $\mathrm{C}_{20} \mathrm{H}_{30} \mathrm{~S}, \mathrm{C}_{27} \mathrm{H}_{44} \mathrm{~S}$ and $\mathrm{C}_{31} \mathrm{H}_{52} \mathrm{~S}$, belonging to the $\mathrm{S}$ class, with a DBE value of 6 . Figure 8 shows some suggested structures for the above mentioned assignments and the assignments of the three other high intensity DBEs (7, 8 and 9) with the same carbon atom number in their chemical formula. As is shown in this figure, such compounds are expected to be benzothiophenes (BTs) or dibenzothiophenes (DBTs) with a different degree of alkylation. The high ionization affinity of BTs and DBTs using APPI(+) is frequently reported in the literature and is matching with the observed results of this study.

According to the available literature, most of the expected compounds are to be in the lower DBE range (below 10) with a high degree of alkylation [9]. To date, most of the GC intermediated studies on different petroleum samples have also shown the alkylated BTs, DBTs or maximum smaller alkylated benzonaphtothiophene (BNTs) as the biggest sulfur-containing heterocyclic structures $[17,38]$. Therefore, most of the detected compounds in this study (e.g., assignments with higher DBEs up to 30 or a higher carbon number up to 80 ) are off the limit of any GC intermediated study and were neglected compounds in the saturate fraction. These results are contradicting NMR studies [46], which indicated that the saturate fraction contains no aromaticity and the aromaticity factor of crude oil is only related to the other fractions.

When it comes to the sulfur-containing heterocycles of the petroleum, it is very important to have a fair knowledge about the variety of all present structures of these compounds. The importance of such information is emphasized when it comes to the planning for the upstream and downstream processes of a specific petroleum sample (i.e., desulfurization process, prediction of corrosion, complying with environmental protection limits). Therefore, the results of this study shows that the saturate fraction contains way more compounds than what is presented in the previous studies using GC techniques. 
<smiles>CCCCCCCCCCCCCCCCCC</smiles>

Chemical Formula: $\mathrm{C}_{20} \mathrm{H}_{30} \mathrm{~S}$ DBE: 6

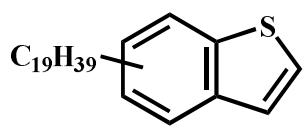

Chemical Formula: $\mathrm{C}_{27} \mathrm{H}_{44} \mathrm{~S}$ DBE: 6<smiles>CCCCCCCCCCCCCCCCCCCC</smiles>

Chemical Formula: $\mathrm{C}_{31} \mathrm{H}_{52} \mathrm{~S}$ DBE: 6

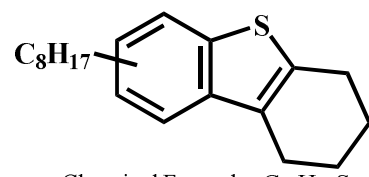

Chemical Formula: $\mathrm{C}_{20} \mathrm{H}_{28} \mathrm{~S}$ DBE: 7

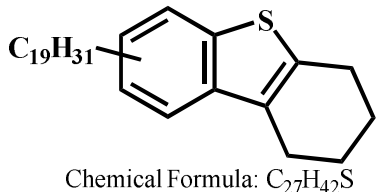

DBE: 7

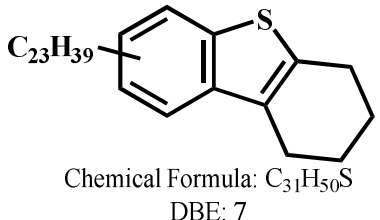

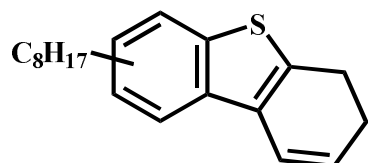

Chemical Formula: $\mathrm{C}_{20} \mathrm{H}_{26} \mathrm{~S}$ DBE: 8

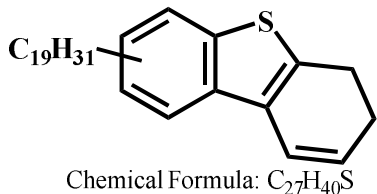

DBE: 8

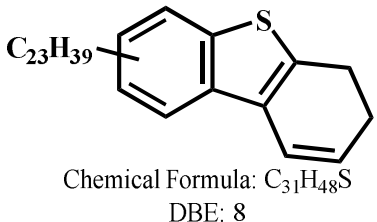

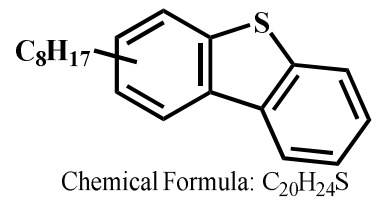

DBE: 9

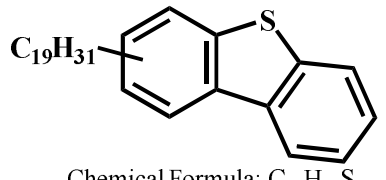

Chemical Formula: $\mathrm{C}_{27} \mathrm{H}_{38} \mathrm{~S}$ DBE: 9

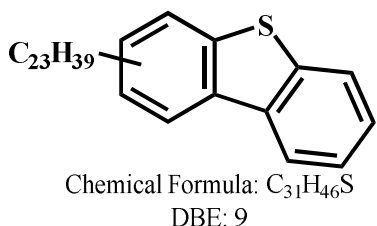

Figure 8. Suggested structures for some of the assignments of an S class for APPI(+) measurements of saturates from Arabic medium oil. The presented assignments are three of the most abundant peaks in the APPI(+) spectrum from DBE 6, and their related higher DBE assignments with the same carbon atom numbers in their chemical formula.

\section{Conclusions}

The saturate fraction is one of the neglected fractions in crude oil studies. Direct infusion UHRMS analysis is a powerful analytical tool which to date has not been applied in saturate fraction studies. This study showed that despite the common knowledge, a wide range of compounds containing different heteroatoms, with a considerable degree of unsaturation, are present in the saturate fraction. The detected sulfur-containing compounds in this study are shown to belong to a wide variety of sulfur species with different structures. Some of the detected sulfur-containing compounds in this study were (cyclic) sulfides or mercaptanes and thiophenic compounds with a wide range of alkylation and unsaturation degree. These compounds are exceeding the carbon number and DBE values of the so-far reported compounds in crude oil studies using GC techniques [47]. The presented results revealed the importance of direct infusion UHRMS analysis using different ionization techniques by means of gaining a clear image of the saturate fraction. Therefore, such studies are needed to be further considered for analysis of this fraction.

Author Contributions: Z.F. performed the experiments, analyzed the data; wrote the initial draft; W.S. conceived research, supervised the project, corrected and edited the manuscript.

Funding: This research received no external funding.

Conflicts of Interest: The authors declare no conflict of interest.

\section{References}

1. Cho, Y.; Na, J.-G.; Nho, N.-S.; Kim, S.; Kim, S. Application of Saturates, Aromatics, Resins, and Asphaltenes Crude Oil Fractionation for Detailed Chemical Characterization of Heavy Crude Oils by Fourier Transform Ion Cyclotron Resonance Mass Spectrometry Equipped with Atmospheric Pressure Photoionization. Energy Fuels 2012, 26, 2558-2565.

2. Vetere, A.; Schrader, W. Mass Spectrometric Coverage of Complex Mixtures: Exploring the Carbon Space of Crude Oil. ChemistrySelect 2017, 2, 849-853. [CrossRef]

3. Gaspar, A.; Zellermann, E.; Lababidi, S.; Reece, J.; Schrader, W. Characterization of Saturates, Aromatics, Resins, and Asphaltenes Heavy Crude Oil Fractions by Atmospheric Pressure Laser Ionization Fourier Transform Ion Cyclotron Resonance Mass Spectrometry. Energy Fuels 2012, 26, 3481-3487. [CrossRef] 
4. $\quad$ Duyck, C.; Miekeley, N.; Da Silveira, C.L.P.; Aucélio, R.Q.; Campos, R.C.; Grinberg, P.; Brandão, G.P. The determination of trace elements in crude oil and its heavy fractions by atomic spectrometry. Spectrochim. Acta Part B At. Spectrosc. 2007, 62, 939-951. [CrossRef]

5. Akmaz, S.; Iscan, O.; Gurkaynak, M.A.; Yasar, M. The Structural Characterization of Saturate, Aromatic, Resin, and Asphaltene Fractions of Batiraman Crude Oil. Pet. Sci. Technol. 2011, 29, 160-171. [CrossRef]

6. Jewell, D.M.; Weber, J.H.; Bunger, J.W.; Plancher, H.; Latham, D.R. Ion-exchange, coordination, and adsorption chromatographic separation of heavy-end petroleum distillates. Anal. Chem. 1972, 44, 1391-1395. [CrossRef]

7. Kharrat, A.M.; Zacharia, J.; Cherian, V.J.; Anyatonwu, A. Issues with Comparing SARA Methodologies. Energy Fuels 2007, 21, 3618-3621. [CrossRef]

8. Fan, T.; Buckley, J.S. Rapid and Accurate SARA Analysis of Medium Gravity Crude Oils. Energy Fuels 2002, 16, 1571-1575. [CrossRef]

9. Bastow, T.P.; Van Aarssen, B.G.; Lang, D. Rapid small-scale separation of saturate, aromatic and polar components in petroleum. Org. Geochem. 2007, 38, 1235-1250. [CrossRef]

10. Santos, J.M.; Vetere, A.; Wisniewski, A.; Eberlin, M.N.; Schrader, W. Comparing Crude Oils with Different API Gravities on a Molecular Level Using Mass Spectrometric Analysis. Part 2: Resins and Asphaltenes. Energies 2018, 11, 2767. [CrossRef]

11. Gáspár, A.; Zellermann, E.; Lababidi, S.; Reece, J.; Schrader, W. Impact of Different Ionization Methods on the Molecular Assignments of Asphaltenes by FT-ICR Mass Spectrometry. Anal. Chem. 2012, 84, 5257-5267. [CrossRef] [PubMed]

12. Bissada, K.K.A.; Tan, J.; Szymczyk, E.; Darnell, M.; Mei, M. Group-type characterization of crude oil and bitumen. Part I: Enhanced separation and quantification of saturates, aromatics, resins and asphaltenes (SARA). Org. Geochem. 2016, 95, 21-28. [CrossRef]

13. Wang, Z.; Fingas, M.; Sergy, G. Chemical Characterization of Crude Oil Residues from an Arctic Beach by GC/MS and GC/FID. Environ. Sci. Technol. 1995, 29, 2622-2631. [CrossRef] [PubMed]

14. Wang, Z.D.; Fingas, M.; Sigouin, L. Characterization and source identification of an unknown spilled oil using fingerprinting techniques by GC-MS and GC-FID. Lc Gc N. Am. 2000, 18, 1058-1067.

15. Oudot, J.; Merlin, F.; Pinvidic, P. Weathering rates of oil components in a bioremediation experiment in estuarine sediments. Mar. Environ. Res. 1998, 45, 113-125. [CrossRef]

16. Klein, G.C.; Angström, A.; Rodgers, R.P.; Marshall, A.G. Use of Saturates/Aromatics/Resins/Asphaltenes (SARA) Fractionation To Determine Matrix Effects in Crude Oil Analysis by Electrospray Ionization Fourier Transform Ion Cyclotron Resonance Mass Spectrometry. Energy Fuels 2006, 20, 668-672. [CrossRef]

17. Schwemer, T.; Rüger, C.P.; Sklorz, M.; Zimmermann, R. Gas Chromatography Coupled to Atmospheric Pressure Chemical Ionization FT-ICR Mass Spectrometry for Improvement of Data Reliability. Anal. Chem. 2015, 87, 11957-11961. [CrossRef]

18. Kondyli, A.; Schrader, W. High-resolution GC/MS studies of a light crude oil fraction. J. Mass Spectrom. 2019, 54, 47-54. [CrossRef]

19. Panda, S.K.; Schrader, W.; Andersson, J.T. Fourier transform ion cyclotron resonance mass spectrometry in the speciation of high molecular weight sulfur heterocycles in vacuum gas oils of different boiling ranges. Anal. Bioanal. Chem. 2008, 392, 839-848. [CrossRef]

20. Knolhoff, A.M.; Callahan, J.H.; Croley, T.R. Mass Accuracy and Isotopic Abundance Measurements for HR-MS Instrumentation: Capabilities for Non-Targeted Analyses. J. Am. Soc. Mass Spectrom. 2014, 25, 1285-1294. [CrossRef]

21. Lozano, D.C.P.; Gavard, R.; Arenas-Diaz, J.P.; Thomas, M.J.; Stranz, D.D.; Mejía-Ospino, E.; Guzman, A.; Spencer, S.E.F.; Rossell, D.; Barrow, M.P. Pushing the analytical limits: New insights into complex mixtures using mass spectra segments of constant ultrahigh resolving power. Chem. Sci. 2019, 10, 6966-6978. [CrossRef]

22. Cho, Y.; Qi, Y.; O'Connor, P.B.; Barrow, M.P.; Kim, S. Application of phase correction to improve the interpretation of crude oil spectra obtained using $7 \mathrm{~T}$ Fourier transform ion cyclotron resonance mass spectrometry. J. Am. Soc. Mass Spectrom. 2014, 25, 154-157. [CrossRef] [PubMed]

23. Dier, T.K.F.; Egele, K.; Fossog, V.; Hempelmann, R.; Volmer, D.A. Enhanced Mass Defect Filtering To Simplify and Classify Complex Mixtures of Lignin Degradation Products. Anal. Chem. 2016, 88, 1328-1335. [CrossRef] [PubMed] 
24. Owen, B.C.; Haupert, L.J.; Jarrell, T.M.; Marcum, C.L.; Parsell, T.H.; Abu-Omar, M.M.; Bozell, J.J.; Black, S.K.; Kenttämaa, H.I. High-Performance Liquid Chromatography/High-Resolution Multiple Stage Tandem Mass Spectrometry Using Negative-Ion-Mode Hydroxide-Doped Electrospray Ionization for the Characterization of Lignin Degradation Products. Anal. Chem. 2012, 84, 6000-6007. [CrossRef] [PubMed]

25. Eugene, A.J.; Guzman, M.I. Reactivity of Ketyl and Acetyl Radicals from Direct Solar Actinic Photolysis of Aqueous Pyruvic Acid. J. Phys. Chem. A 2017, 121, 2924-2935. [CrossRef]

26. Guricza, L.M.; Schrader, W. New Separation Approach for Asphaltene Investigation: Argentation Chromatography Coupled with Ultrahigh-Resolution Mass Spectrometry. Energy Fuels 2015, 29, 6224-6230. [CrossRef]

27. Guricza, L.M.; Schrader, W. Argentation chromatography coupled to ultrahigh-resolution mass spectrometry for the separation of a heavy crude oil. J. Chromatogr. A 2017, 1484, 41-48. [CrossRef]

28. Guricza, L.M.; Schrader, W. Electrospray ionization for determination of non-polar polyaromatic hydrocarbons and polyaromatic heterocycles in heavy crude oil asphaltenes. J. Mass Spectrom. 2015, 50, 549-557. [CrossRef]

29. Konermann, L.; Ahadi, E.; Rodriguez, A.D.; Vahidi, S. Unraveling the mechanism of electrospray ionization. Anal. Chem. 2013, 85, 2-9. [CrossRef]

30. Schäfer, M.; Drayß, M.; Springer, A.; Zacharias, P.; Meerholz, K. Radical Cations in Electrospray Mass Spectrometry: Formation of Open-Shell Species, Examination of the Fragmentation Behaviour in ESI-MSn and Reaction Mechanism Studies by Detection of Transient Radical Cations. Eur. J. Org. Chem. 2007, 2007, 5162-5174. [CrossRef]

31. Headley, J.V.; Peru, K.M.; Barrow, M.P. Advances in mass spectrometric characterization of naphthenic acids fraction compounds in oil sands environmental samples and crude oil—A review. Mass Spectrom. Rev. 2016, 35, 311-328. [CrossRef] [PubMed]

32. Byrdwell, W.C. Atmospheric pressure chemical ionization mass spectrometry for analysis of lipids. Lipids 2001, 36, 327-346. [CrossRef] [PubMed]

33. Byrdwell, W.C. The bottom-up solution to the triacylglycerol lipidome using atmospheric pressure chemical ionization mass spectrometry. Lipids 2005, 40, 383-417. [CrossRef] [PubMed]

34. Panda, S.K.; Andersson, J.T.; Schrader, W. Characterization of Supercomplex Crude Oil Mixtures: What Is Really in There? Angew. Chem. 2009, 121, 1820-1823. [CrossRef]

35. Chiaberge, S.; Fiorani, T.; Savoini, A.; Bionda, A.; Ramello, S.; Pastori, M.; Cesti, P. Classification of crude oil samples through statistical analysis of APPI FTICR mass spectra. Fuel Process. Technol. 2013, 106, 181-185. [CrossRef]

36. Bae, E.; Na, J.G.; Chung, S.H.; Kim, H.S.; Kim, S. Identification of about 30000 Chemical Components in Shale Oils by Electrospray Ionization (ESI) and Atmospheric Pressure Photoionization (APPI) Coupled with 15 T Fourier Transform Ion Cyclotron Resonance Mass Spectrometry (FT-ICR MS) and a Comparison to Conventional Oil. Energy Fuels 2010, 24, 2563-2569.

37. Javadli, R.; de Klerk, A. Desulfurization of Heavy Oil-Oxidative Desulfurization (ODS) As Potential Upgrading Pathway for Oil Sands Derived Bitumen. Energy Fuels 2012, 26, 594-602. [CrossRef]

38. Hua, R.; Wang, J.; Kong, H.; Liu, J.; Lü, X.; Xu, G. Analysis of sulfur-containing compounds in crude oils by comprehensive two-dimensional gas chromatography with sulfur chemiluminescence detection. J. Sep. Sci. 2004, 27, 691-698. [CrossRef] [PubMed]

39. Liu, P.; Shi, Q.; Pan, N.; Zhang, Y.; Chung, K.H.; Zhao, S.; Xu, C. Distribution of Sulfides and Thiophenic Compounds in VGO Subfractions: Characterized by Positive-Ion Electrospray Fourier Transform Ion Cyclotron Resonance Mass Spectrometry. Energy Fuels 2011, 25, 3014-3020. [CrossRef]

40. Řezanka, T. Analysis of very long chain polyunsaturated fatty acids using high-performance liquid chromatography-Atmospheric pressure chemical ionization mass spectrometry. Biochem. Syst. Ecol. 2000, 28, 847-856. [CrossRef]

41. Řezanka, T. Identification of very long chain fatty acids by atmospheric pressure chemical ionization liquid chromatography-mass spectroscopy from green alga Chlorella kessleri. J. Sep. Sci. 2002, 25, 1332-1336. [CrossRef]

42. Krogh, K.A.; Vejrup, K.V.; Mogensen, B.B.; Halling-Sørensen, B. Liquid chromatography-mass spectrometry method to determine alcohol ethoxylates and alkylamine ethoxylates in soil interstitial water, ground water and surface water samples. J. Chromatogr. A 2002, 957, 45-57. [CrossRef] 
43. Cho, Y.; Kim, Y.H.; Kim, S. Planar Limit-Assisted Structural Interpretation of Saturates/Aromatics/Resins/Asphaltenes Fractionated Crude Oil Compounds Observed by Fourier Transform Ion Cyclotron Resonance Mass Spectrometry. Anal. Chem. 2011, 83, 6068-6073. [CrossRef] [PubMed]

44. Cai, S.-S.; Syage, J.A.; Hanold, K.A.; Balogh, M.P. Ultra Performance Liquid Chromatography-Atmospheric Pressure Photoionization-Tandem Mass Spectrometry for High-Sensitivity and High-Throughput Analysis of U.S. Environmental Protection Agency 16 Priority Pollutants Polynuclear Aromatic Hydrocarbons. Anal. Chem. 2009, 81, 2123-2128. [CrossRef] [PubMed]

45. Itoh, N.; Aoyagi, Y.; Yarita, T. Optimization of the dopant for the trace determination of polycyclic aromatic hydrocarbons by liquid chromatography/dopant-assisted atmospheric-pressure photoionization/mass spectrometry. J. Chromatogr. A 2006, 1131, 285-288. [CrossRef] [PubMed]

46. Sánchez-Minero, F.; Ancheyta, J.; Silva-Oliver, G.; Flores-Valle, S. Predicting SARA composition of crude oil by means of NMR. Fuel 2013, 110, 318-321. [CrossRef]

47. Hegazi, A.H.; Andersson, J.T. Limitations to GC-MS Determination of Sulfur-Containing Polycyclic Aromatic Compounds in Geochemical, Petroleum, and Environmental Investigations. Energy Fuels 2007, 21, 3375-3384. [CrossRef]

(C) 2019 by the authors. Licensee MDPI, Basel, Switzerland. This article is an open access article distributed under the terms and conditions of the Creative Commons Attribution (CC BY) license (http://creativecommons.org/licenses/by/4.0/). 